\title{
Normalized endothelial function but sustained cardiovascular risk profile 11 years following a pregnancy complicated by preeclampsia
}

\author{
Eva Östlund ${ }^{1}$, Maha Al-Nashi ${ }^{2}$, Rangeen Rafik Hamad ${ }^{2}$, Anders Larsson ${ }^{3}$, Maria Eriksson ${ }^{4}$, \\ Katarina Bremme ${ }^{2}$ and Thomas Kahan ${ }^{5}$
}

Women with a history of preeclampsia are at increased risk of future cardiovascular disease. Preeclampsia is associated with elevated blood pressure, inflammation and endothelial dysfunction, and these findings remain 1 year after delivery. Whether these abnormalities persist long after delivery, and whether they may contribute to future cardiovascular disease, is not well studied. We studied 15 women with a history of preeclampsia and 16 matched controls with an uncomplicated pregnancy 11 years following the index pregnancy; all had also been previously examined at 1 year. We assessed arterial stiffness (pulse wave analysis), $24 \mathrm{~h}$ ambulatory blood pressure and endothelial function (forearm flow-mediated dilatation and pulse wave analysis following $\beta$ receptor agonist provocation), and determined markers of glucose and lipid metabolism, inflammation and vascular function. The preeclampsia group had higher blood pressures and reduced night/day blood pressure ratios, increased body mass index and reduced glucose tolerance, and increased levels of tissue necrosis factor receptor 1 and intracellular adhesion molecule-1, suggesting inflammatory and vascular activation. However, the endothelial impairment observed in the preeclampsia group at 1 year was normalized at 11 years, whereas the control group remained unchanged during follow-up. Our findings of higher blood pressures, impaired glucose tolerance and normalization of endothelial function 11 years after preeclampsia suggest cardiovascular risk factors present already before pregnancy to be more important than permanent endothelial damage for the increased risk of future cardiovascular complications in women with a history of preeclampsia. Hypertension Research (2013) 36, 1081-1087; doi:10.1038/hr.2013.81; published online 15 August 2013

Keywords: arterial function; blood pressure; cardiovascular disease; endothelial function; preeclampsia

\section{INTRODUCTION}

Preeclampsia $(\mathrm{PE})$ affects $\sim 5 \%$ of all pregnancies. It is a multiorgan disorder resulting in hypertension and proteinuria in the mother, and growth restriction in the fetus. Women with a history of PE have an almost fourfold increased risk of hypertension, and a twofold increased risk of ischemic heart disease, stroke, and venous thromboembolism in later life. ${ }^{1}$ Patients with more severe PE are at greater risk. $^{2,3}$

Endothelial dysfunction has a central role in the pathogenesis of PE. Endothelial dysfunction remaining after delivery may cause further vascular dysfunction and future cardiovascular disease. Indeed, studies have demonstrated endothelial dysfunction within a year after a pregnancy complicated with PE. ${ }^{4}$ However, other studies suggest that pre-existing cardiovascular risk factors present already before pregnancy may be more important for the future risk of cardiovascular disease than impaired endothelial function during PE. ${ }^{5}$
If this were the case, one could anticipate that endothelial dysfunction would eventually diminish after pregnancy complicated with PE. However, long-time follow-up studies on endothelial function are lacking.

We have previously shown that women with PE, as compared with women with a normal pregnancy, exhibit endothelial dysfunction, increased blood pressure and metabolic alterations 1 year after a pregnancy. ${ }^{4}$ The aim of this study was to examine these same women again 10-12 years after the index pregnancy to see if these abnormalities remained present.

\section{METHODS}

Subjects and study design

Pregnancy data collected from hospital records were used to include 18 subjects with a pregnancy complicated by a diagnosis of severe PE according to current recommendations. ${ }^{6}$ The PE group was otherwise healthy non-smoking

${ }^{1}$ Division of Obstetrics and Gynecology, Department of Clinical Sciences, Danderyd Hospital, Karolinska Institutet, Stockholm, Sweden; ${ }^{2}$ Division of Obstetrics and Gynecology, Department of Women's and Children's Health, Karolinska Institutet, Stockholm, Sweden; ${ }^{3}$ Department of Medical Sciences, Uppsala University, Uppsala, Sweden; ${ }^{4}$ Department of Clinical Physiology, Karolinska University Hospital, Stockholm, Sweden and ${ }^{5}$ Division of Cardiovascular Medicine, Department of Clinical Sciences, Danderyd Hospital, Karolinska Institutet, Stockholm, Sweden

Correspondence: Professor T Kahan, Department of Cardiology, Danderyd University Hospital Corp, Stockholm, Sweden.

E-mail: thomas.kahan@ds.se

Received 26 March 2013; revised 30 April 2013; accepted 23 May 2013; published online 15 August 2013 
primiparas with a normal blood pressure, normal menstrual cycles, no ongoing hormonal therapy or other drug treatment, no diabetes mellitus, gestational diabetes, coagulation disorders, renal disease or chronic hypertension. The control group consisted of 17 healthy non-smoking women recruited in a similar manner with a normal uncomplicated pregnancy, matched for age, parity and date of delivery. The initial investigations at 1 year were performed at $15 \pm 3$ months following the index pregnancy, as described and reported in detail. $^{4}$

For the current study, all women were again invited for examinations, which were performed $11.2 \pm 0.6$ years following the index pregnancy. Only two in the PE group and one in the control group were unwilling to attend. Background characteristics are given in Table 1. None in the PE group used oral contraceptives but one had an intrauterine hormonal device; the remaining had regular menstruations. Nine women had been pregnant again: one more pregnancy in seven women (two with recurrence of PE), two more in one and three more pregnancies in one woman. Thus, in the PE group the current examinations were performed $7.9 \pm 3.3$ years following the last pregnancy. In the control group, none used oral contraceptives but six had an intrauterine hormonal device; the remaining had regular menstruations. All control subjects except one had been pregnant again: one more pregnancy in 11 women, two more in three and three more pregnancies in one woman (none with $\mathrm{PE}$ ). Thus, in the control group the current examinations were performed $6.6 \pm 2.4$ years following the last pregnancy.

Participants arrived in the morning after fasting overnight. They were asked to refrain from caffeine-containing beverages, fruit juices or vitamin $\mathrm{C}$, and

\section{Table 1 Clinical characteristics}

\begin{tabular}{|c|c|c|c|}
\hline & Controls & Preeclampsia & P-value \\
\hline $\begin{array}{l}n \\
\text { Index pregnancy }\end{array}$ & \multicolumn{2}{|c|}{ Index pregnancy } & - \\
\hline Pregnancy length (days) & $281 \pm 6$ & $245 \pm 6$ & $<0.001$ \\
\hline Birth weight, g & $3766 \pm 195$ & $2557 \pm 208$ & $<0.001$ \\
\hline \multicolumn{4}{|l|}{11 Years after delivery } \\
\hline Age, years & $41.2 \pm 3.2$ & $39.4 \pm 3.6$ & 0.14 \\
\hline Family history of hypertension & 8 & 9 & 0.48 \\
\hline Family history of preeclampsia & 0 & 3 & 0.075 \\
\hline $\begin{array}{l}\text { Family history of coronary } \\
\text { artery disease and/or stroke }\end{array}$ & 5 & 6 & $>0.5$ \\
\hline $\begin{array}{l}\text { Family history of venous } \\
\text { thromboembolism }\end{array}$ & 2 & 5 & 0.20 \\
\hline Parity & $2.5 \pm 0.7$ & $1.8 \pm 0.9$ & 0.18 \\
\hline Current smoker & 1 & 0 & $>0.5$ \\
\hline Current hypertension & 0 & 1 & 0.45 \\
\hline Current diabetes mellitus & 0 & 0 & - \\
\hline Body mass index, $\mathrm{kg} \mathrm{m}^{-2}$ & $23.3 \pm 3.1$ & $25.8 \pm 6.1$ & 0.099 \\
\hline Waist/hip ratio & $0.80 \pm 0.04$ & $0.82 \pm 0.06$ & 0.094 \\
\hline Total cholesterol, $\mathrm{mmoll}^{-1}$ & $4.80 \pm 0.76$ & $4.72 \pm 1.17$ & $>0.5$ \\
\hline LDL cholesterol, mmol I-1 & $3.10 \pm 0.58$ & $3.03 \pm 1.08$ & $>0.5$ \\
\hline HDL cholesterol mmoll-1 & $1.44 \pm 0.39$ & $1.39 \pm 0.24$ & $>0.5$ \\
\hline ApoB/ApoA1 & $0.64 \pm 0.44$ & $0.49 \pm 0.18$ & 0.22 \\
\hline Glucose, $\mathrm{mmol}^{-1}$ & $4.87 \pm 0.48$ & $4.98 \pm 0.41$ & 0.49 \\
\hline Insulin, pmol I-1 & $29.6 \pm 14.8$ & $46.7 \pm 39.1$ & 0.124 \\
\hline HOMA & $6.57 \pm 3.83$ & $10.92 \pm 10.79$ & 0.103 \\
\hline QUICKI & $0.48 \pm 0.06$ & $0.45 \pm 0.05$ & 0.093 \\
\hline Creatinine, $\mathrm{mmoll}^{-1}$ & $67 \pm 10$ & $67 \pm 12$ & 0.88 \\
\hline Cystatin $\mathrm{C}, \mathrm{mgl}^{-1}$ & $0.85 \pm 0.11$ & $0.84 \pm 0.13$ & 0.80 \\
\hline $\begin{array}{l}\text { Estimated glomerular filtration } \\
\text { by cystatin } \mathrm{C}, \mathrm{ml} \mathrm{min}^{-1} 1.73 \mathrm{~m}^{-2}\end{array}$ & $89 \pm 4$ & $87 \pm 6$ & 0.33 \\
\hline
\end{tabular}

Abbreviations: HDL, high-density lipoprotein; HOMA, homeostasis model assessment; LDL, lowdensity lipoprotein; QUICKI, quantitative insulin sensitivity check index.

Mean values \pm s.d. or $n$, as appropriate. HOMA formula as $0.167 \times \mathrm{mmoll}^{-1}$ glucose $\times$ pmoll ${ }^{-1}$ insulin/22.5; QUICKI formula as $1 / \log \mathrm{mmoll}^{-1}$ glucose $\times$ log pmoll-1. any medication. Examinations were performed in the supine position in a quiet room kept at constant temperature following a 20-min period of rest. Blood was obtained from an antecubital vein into Vacutainer tubes (Becton Dickinson Cedex, Meylan, France) containing EDTA on ice and centrifuged at $2250 \mathrm{~g}$ for $20 \mathrm{~min}$ at $+4{ }^{\circ} \mathrm{C}$, or containing citrate or no additive, as appropriate, and centrifuged at $2250 \mathrm{~g}$ for $20 \mathrm{~min}$ at $+20^{\circ} \mathrm{C}$. Aliquots of serum and plasma were stored at $-70{ }^{\circ} \mathrm{C}$ until further analyses.

All participants gave their written consent to participate in the study. The Ethics Committee in Stockholm approved of the study, and all procedures followed were in accordance with institutional guidelines.

\section{Blood pressure measurements}

Brachial blood pressure was obtained in the supine position by an oscillometric device (OMRON 705IT, OMRON Healthcare, Kyoto, Japan) on the right arm with an appropriately sized cuff as a mean of three readings $1 \mathrm{~min}$ apart. Ambulatory blood pressure during $24 \mathrm{~h}$ was recorded with a Spacelabs 90207 device (Spacelab Healthcare, Issaquah, WA, USA) and a cuff of appropriate size on the non-dominant arm. Readings were made every $20 \mathrm{~min}$ throughout. Default automatic editing was used and all recordings had $>80 \%$ valid measurements. The recorded values were first averaged for each hour, and values for daytime, nighttime and $24 \mathrm{~h}$ were subsequently calculated from these hourly averages. We defined daytime as 1000-2000 hours, and nighttime as 0000-0600 hours.

\section{Pulse wave analysis}

Applanation tonometry was performed using a SphygmoCor device (AtCor Pty, West Ryde, NSW, Australia) according to current recommendations.? Radial artery waveforms were calibrated using brachial systolic and diastolic blood pressures; the central aortic waveform was calculated by device software using the generalized transfer function, and central blood pressure values were derived. The augmentation index was measured through the software. Recordings were then repeated at the level of the common carotid artery and the femoral artery, and pulse wave velocity was calculated from the direct (carotid-to-radial and carotid-to-femoral) path length.

\section{Assessment of endothelial function}

Endothelium-dependent flow-mediated vasodilatation (FMD) was assessed by ischemia-induced reactive hyperemia in the non-dominant arm according to current recommendations. ${ }^{8}$ Vasodilatation was induced by inflation of a pneumatic tourniquet placed around the forearm to a pressure of $250 \mathrm{~mm} \mathrm{Hg}$ for $5 \mathrm{~min}$, followed by release. The brachial artery diameter was measured by a Vivid 7 Dimension (GE Medical System, Horten, Norway) ultrasound device with a 9-MHz linear transducer. All images were stored for later analyses. The mean values of three measurements of arterial diameter performed at end diastole were calculated at rest and at 30,60 and $90 \mathrm{~s}$ after cuff release. The relative increase in diameter of the artery to the maximal value observed was taken as a measure of FMD. After a washout period of at least $10 \mathrm{~min}$ to regain stable resting conditions, $0.4 \mathrm{mg}$ glyceryl trinitrate (Nitrolingual, G Pohl-Boskamp GmbH, Hohenlockstedt, Germany) given as sublingual spray was used to assess endothelium-independent vasodilatation. Relative changes in brachial artery diameter were calculated from rest to $4 \mathrm{~min}$ following drug administration. The inter assay coefficient of variation for FMD in our laboratory is $15 \%(n=20)$.

Endothelial function was also assessed on an adjacent day by $\beta-2$ adrenergic agonist-induced changes in the pulse waveform, as described elsewhere. ${ }^{9}$ Radial artery pulse waves were recorded by applanation tonometry, as described above. The maximal systolic peak and the reflected waves were identified by the calculations of the first and second derivative of the pulse curve. The relative height of the diastolic reflected wave (that is, the reflection index) was used as an index of endothelial function. ${ }^{10}$ After a recording under resting conditions, $0.25 \mathrm{mg}$ terbutaline (Bricanyl, AstraZeneca, Mölndal, Sweden) was given subcutaneously in the upper forearm and reevaluation of the pulse wave was performed after 15 and $20 \mathrm{~min}$. The maximal relative change was used. A large reduction of the reflection index indicates a good response. 


\section{Biochemical analyses}

Routine blood chemistry was assessed by standard procedures. Creatinine, cystatin $\mathrm{C}$ and high-sensitive C-reactive protein (hs-CRP) were measured in plasma by enzymatic colorimetric methods on an Architect Ci8200 analyzer (Abbott, Abbot Park, IL, USA). Insulin was measured in serum by an immunoassay on a Modular analyzers E170 module (Roche Diagnostics, Mannheim, Germany).

Amino-terminal pro-brain natriuretic peptide (NT-pro-BNP) was analyzed on a Cobas EE instrument (Roche Diagnostics). Pentraxin 3, tissue necrosis factor (TNF) receptor 1, intercellular adhesion molecule-1 (ICAM), vascular adhesion molecule-1 (VCAM), soluble fms-like tyrosine kinase-1, placental growth factor (PlGF), cathepsin $\mathrm{B}$ and cathepsin $\mathrm{S}$ were analysed, by enzymelinked immunosorbent assays (R\&D Systems, Minneapolis, MN, USA). These biomarkers were analyzed in plasma. Coefficients of variation were all $<8 \%$.

Glucose tolerance was calculated by the homeostasis model assessment (HOMA) as $0.167 \times \mathrm{mmoll}^{-1}$ fasting glucose $\times \mathrm{pmoll}^{-1}$ fasting insulin/ $22.5,{ }^{11}$ and by the quantitative insulin sensitivity check index (QUICKI) formula as $1 / \log \mathrm{mmoll}^{-1}$ fasting glucose $\times \log$ pmoll $^{-1}$ fasting insulin. ${ }^{12}$ Estimated glomerular filtration rate was calculated from cystatin $\mathrm{C}$ measurements.

\section{Statistics}

Results are presented as mean values \pm s.d. or proportions, as appropriate. Skewed variables were logarithmically transformed. Student's $t$-test or a twoway repeated measures analysis of variance were used to assess continuous data, and the $\chi^{2}$-test was used for variables in contingency tables. Pearson's correlation coefficient was used to measure the association between the variables. A probability $(P)<0.05$ was considered statistically significant. JMP version 10 (SAS Institute Inc., Cary, NC, USA) was used.

\section{RESULTS}

General

Demographic and baseline characteristics were comparable in the two study groups (Table 1). However, the PE group was somewhat younger and had a somewhat higher body mass index and greater waist-hip ratio.

Blood pressure and vascular function

The PE group had slightly but consistently higher blood pressure levels than the control group (Table 2). However, only $24 \mathrm{~h}$

Table 2 Blood pressures and vascular function

\begin{tabular}{lccc}
\hline & Controls & Preeclampsia & P-value \\
\hline Heart rate, beats per min & $58 \pm 9$ & $59 \pm 11$ & 0.71 \\
Supine systolic BP, mm Hg & $111 \pm 11$ & $117 \pm 14$ & 0.18 \\
Supine diastolic BP. mm Hg & $70 \pm 2$ & $75 \pm 2$ & 0.16 \\
Central systolic BP, mm Hg & $101 \pm 12$ & $108 \pm 15$ & 0.16 \\
Central diastolic BP, mm Hg & $71 \pm 10$ & $76 \pm 10$ & 0.23 \\
24 h ABP, mean 24 h systolic BP, mm Hg & $112 \pm 11$ & $117 \pm 11$ & 0.22 \\
24 h ABP, mean 24h diastolic BP, mm Hg & $71 \pm 9$ & $75 \pm 8$ & 0.28 \\
24h ABP, mean day systolic BP, mm Hg & $120 \pm 11$ & $123 \pm 12$ & 0.47 \\
24 h ABP, mean day diastolic BP, mm Hg & $78 \pm 9$ & $80 \pm 9$ & 0.52 \\
24h ABP, mean night systolic BP, mm Hg & $100 \pm 10$ & $108 \pm 10$ & 0.030 \\
24h ABP, mean night diastolic BP, mm Hg & $60 \pm 9$ & $65 \pm 7$ & 0.073 \\
Night/day ratio, systolic BP & $0.76 \pm 0.05$ & $0.81 \pm 0.06$ & 0.022 \\
Night/day ratio, diastolic BP & $0.84 \pm 0.04$ & $0.88 \pm 0.04$ & 0.021 \\
Pulse wave velocity, carotid-femoral, m s & $6.32 \pm 0.46$ & $6.26 \pm 1.01$ & 0.83 \\
Pulse wave velocity, carotid-radial, m s ${ }^{-1}$ & $7.91 \pm 1.11$ & $8.13 \pm 1.06$ & 0.58 \\
Augmentation index, \% & $21.1 \pm 10.3$ & $25.0 \pm 8.2$ & 0.26
\end{tabular}

Abbreviations: ABP; ambulatory blood pressure; BP; blood pressure.

Mean values \pm s.d. in 15 patients with a history of preeclampsia and in 16 control subjects with uncomplicated pregnancy. ambulatory blood pressure values at night, and the night/day ratios were significantly different between the groups (Table 2). Measurements of arterial stiffness (that is, pulse wave velocity and augmentation index) were similar in the two study groups (Table 2).

\section{Endothelial function}

Endothelial-dependent and -independent vasodilatation, induced by post ischemic hyperemia and glyceryl trinitrate, respectively, was similar in the two study groups (Figure 1). Also the ratios, post ischemic hyperemia-/glyceryl trinitrate-induced response were similar in the PE group and the control group $(0.40 \pm 0.24$ and $0.34 \pm 0.16$, respectively). When the early and severe PE patients were compared with the remaining PE patients, post ischemic hyperemia $(9.9 \pm 2.6 \%$ vs. $11.3 \pm 7.0 \%$ increase), glyceryl trinitrate-induced vasodilatation $(28.3 \pm 9.8 \%$ vs. $29.6 \pm 10.3 \%$ increase $)$ and the ratios post ischemic hyperemia-/glyceryl trinitrate-induced response $(0.41 \pm 0.26$ vs. $0.41 \pm 0.24$ ) were similar (Figure 1). Endothelial function assessed by pulse wave analysis and terbutaline also revealed no difference between the study groups (Figure 1), as the changes in reflectance index by terbutaline in the PE group and the control group were $-10.8 \pm 4.4 \%$ and $-8.6 \pm 2.7 \%$, respectively. Again, when the early
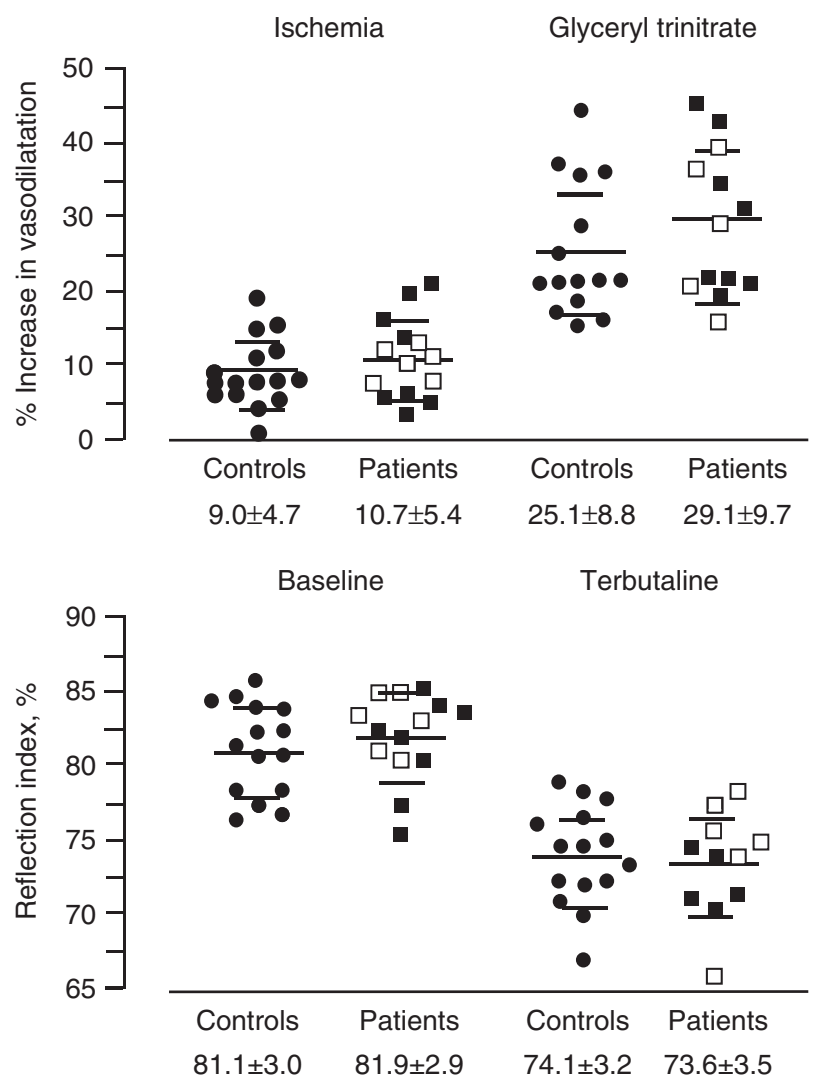

Figure 1 Flow-mediated endothelium-dependent and -independent vasodilatation, induced by post ischemic hyperemia and glyceryl trinitrate (top panel) and endothelial function assessed by pulse wave analysis and the reflectance index before and administration of terbutaline (bottom panel) in patients with preeclampsia (squares) and control subjects (circles) 11 years after the index pregnancy. Mean values \pm s.d. for $11-15$ patients and 14-15 control subjects. Open symbols denote six patients with severe preeclampsia delivered before 34 weeks of gestation. There were no differences between the two study groups. 
and severe patients were compared with the remaining PE patients, the reflectance index before $(74.6 \pm 4.3 \%$ vs. $72.4 \pm 1.8 \%)$ and the reduction after terbutaline $(-9.9 \pm 5.3 \%$ vs. $-11.7 \pm 3.2 \%)$ were similar (Figure 1).

Brachial artery diameters were similar in the two study groups. However, the PE group showed higher forearm blood flow values and systolic flow velocities than the control group (Table 3). Mean forearm blood flow values during hyperemia related to HOMA $\left(r^{2}=0.19 ; P=0.011\right)$, cathepsin $\mathrm{S}\left(r^{2}=0.17 ; P=0.016\right)$ and hsCRP $\left(r^{2}=0.15 ; P=0.018\right)$.

Biochemical markers of inflammation and endothelial function The PE group had higher levels of TNF receptor 1, while other markers of inflammation (leukocyte counts, hs-CRP, pentraxin 3 )

Table 3 Forearm circulatory variables before and during postschemic hyperemia

\begin{tabular}{|c|c|c|c|}
\hline & Control & Preeclampsia & P-value \\
\hline Brachial artery diameter at rest, $\mathrm{mm}$ & $3.05 \pm 0.23$ & $2.93 \pm 0.42$ & 0.231 \\
\hline $\begin{array}{l}\text { Mean systolic blood flow } \\
\text { velocity at rest, } \mathrm{ms}^{-1}\end{array}$ & $0.45 \pm 0.12$ & $0.61 \pm 0.24$ & 0.023 \\
\hline Mean blood flow at rest, $\mathrm{ml} \mathrm{min}^{-1}$ & $25.2 \pm 8.6$ & $48.5 \pm 26.2$ & 0.002 \\
\hline $\begin{array}{l}\text { Increase in mean blood flow } \\
\text { during hyperemia }\end{array}$ & $11.5 \pm 7.8$ & $6.8 \pm 2.6$ & 0.007 \\
\hline $\begin{array}{l}\text { Peak systolic blood flow } \\
\text { velocity at rest, } \mathrm{ms}^{-1}\end{array}$ & $0.81 \pm 0.10$ & $0.90 \pm 0.17$ & 0.072 \\
\hline $\begin{array}{l}\text { Peak systolic blood flow velocity } \\
\text { during hyperemia, } \mathrm{ms}^{-1}\end{array}$ & $1.74 \pm 0.27$ & $2.01 \pm 0.48$ & 0.066 \\
\hline $\begin{array}{l}\text { Peak diastolic blood flow velocity } \\
\text { during hyperemia, } \mathrm{ms}^{-1}\end{array}$ & $1.16 \pm 0.08$ & $1.34 \pm 0.08$ & 0.139 \\
\hline $\begin{array}{l}\text { Peak systolic/diastolic blood flow } \\
\text { velocity during hyperemia, } \mathrm{ms}^{-1}\end{array}$ & $1.53 \pm 0.19$ & $1.53 \pm 0.18$ & 0.940 \\
\hline
\end{tabular}

Mean values \pm s.d. in 15 patients with a pregnancy complicated by preeclampsia and in 16 control subjects with uncomplicated pregnancy. were similar in the two study groups (Table 4). ICAM was increased in the PE group, whereas other markers of endothelial function (that is, VCAM and albumin/creatinine ratio in urine) did not differ between the groups. The placenta markers PlGF and soluble fms-like tyrosine kinase-1 also did not differ between the groups.

\section{Biochemical markers of metabolism}

There was a trend for impaired glucose tolerance in patients with a history of PE (Table 1). Glucose tolerance was inversely related to body mass index (for example, HOMA: $r^{2}=0.58, P<0.001$; QUICKI: $\left.r^{2}=0.26, P<0.01\right)$. Blood lipids, brain natriuretic peptide levels and renal function did not differ between the groups (Table 1).

\section{Table 4 Biochemical findings}

\begin{tabular}{|c|c|c|c|}
\hline & Control & Preeclampsia & P-value \\
\hline Leukocyte counts, $\times 10^{9} \mathrm{I}^{-1}$ & $5.0 \pm 1.1$ & $4.7 \pm 1.5$ & 0.54 \\
\hline Hs-CRP, $\mathrm{mgl}^{-1}$ & $0.92 \pm 0.87$ & $0.76 \pm 0.87$ & 0.62 \\
\hline Pentraxin $3,\left.\mu g\right|^{-1}$ & $8.96 \pm 3.08$ & $9.48 \pm 4.14$ & 0.69 \\
\hline TNF receptor $\left.1 \mu \mathrm{g}\right|^{-1}$ & $1.62 \pm 0.24$ & $1.91 \pm 0.47$ & 0.035 \\
\hline ICAM, $\left.\mu g\right|^{-1}$ & $102 \pm 15$ & $120 \pm 29$ & 0.034 \\
\hline VCAM, $\left.\mu g\right|^{-1}$ & $608 \pm 108$ & $661 \pm 123$ & 0.22 \\
\hline Albumin/creatinine ratio in urine, $\mathrm{mg} \mathrm{mol}^{-1}$ & $0.75 \pm 0.83$ & $0.86 \pm 1.07$ & 0.74 \\
\hline sFIt-1 ng |-1 & $347 \pm 146$ & $370 \pm 124$ & 0.64 \\
\hline PIGF, $\mathrm{ngI}^{-1}$ & $21.2 \pm 6.0$ & $22.2 \pm 5.6$ & 0.66 \\
\hline Cathepsin B, $\left.\mu \mathrm{g}\right|^{-1}$ & $76 \pm 35$ & $74 \pm 25$ & 0.84 \\
\hline Cathepsin S, $\left.\mu \mathrm{g}\right|^{-1}$ & $20 \pm 4$ & $23 \pm 5$ & 0.10 \\
\hline Homocystein $\mu \mathrm{moll}^{-1}$ & $9.1 \pm 2.1$ & $8.7 \pm 1.4$ & 0.60 \\
\hline NT-pro-BNP, ng |-1 & $61 \pm 38$ & $40 \pm 25$ & 0.09 \\
\hline
\end{tabular}

Abbreviations: Hs-CRP, high-sensitive C-reactive protein; ICAM, intercellular adhesion molecule-1; NT-pro-BNP, amino-terminal pro-brain natriuretic peptide; PIGF, placental growth factor; sFlt-1, soluble fms-like tyrosine kinase-1; TNF, tissue necrosis factor; VCAM, vascular adhesion molecule-1.

Mean values \pm s.d. in 15 patients with a history of preeclampsia and in 16 control subjects with uncomplicated pregnancy.
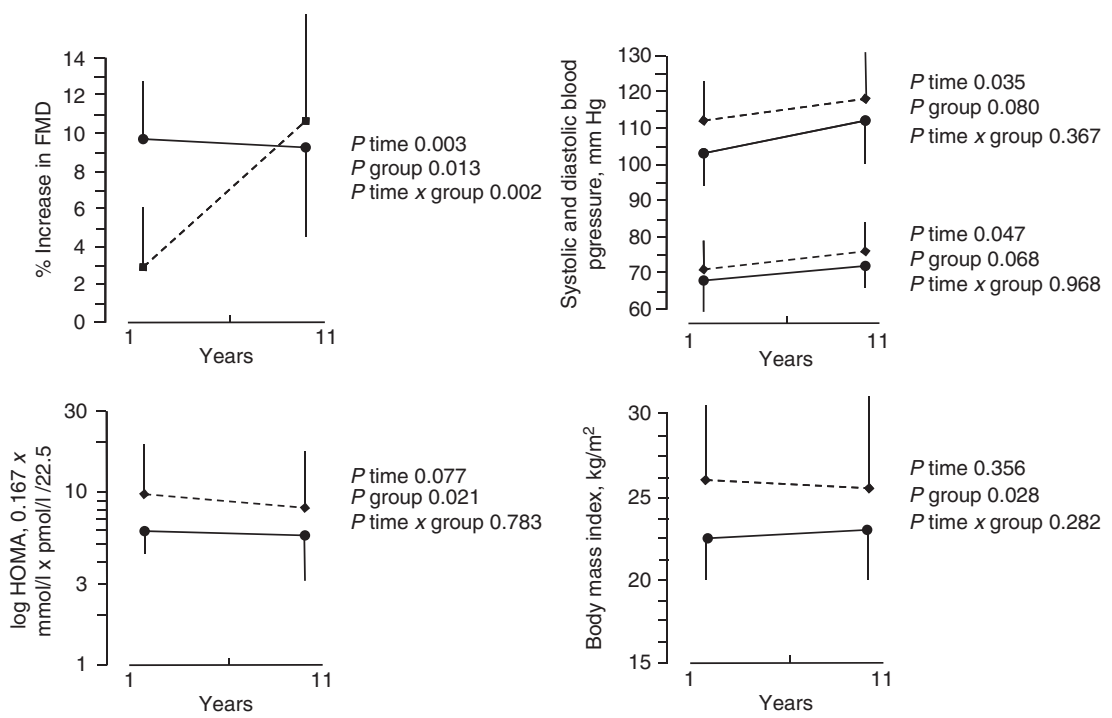

Figure 2 Temporal changes in blood pressure, endothelial function, body weight and glucose tolerance 1 and 11 years after the index pregnancy. Broken lines represent 15 patients with preeclampsia and solid lines 16 control subjects. FMD, flow-mediated dilatation; HOMA, homeostasis model assessment. Mean values and s.d. are presented. 
Comparisons between measurements 1 and 11 years of follow-up Systolic and diastolic blood pressures increased in both study groups during the 11 years of follow-up. Furthermore, blood pressures appeared to be consistently higher the $\mathrm{PE}$ group (Figure 2). Also $24 \mathrm{~h}$ ambulatory blood pressures gave similar results, with a trend for higher systolic and diastolic values in the PE group (data not shown).

Endothelial function assessed by FMD was unchanged in the control group from 1 to 11 years, whereas endothelial function in the PE group was normalized during follow-up (Figure 2).

Hs-CRP decreased from 1 to 11 years $(P<0.001)$, similar in both groups. Also ICAM decreased to a similar extent in both groups from 1 to 11 years $(P<0.001)$, and VCAM decreased in the PE group, as compared with the control group $(P<0.001)$.

Body mass index remained higher in the PE group during followup and the PE group also displayed reduced glucose tolerance (Figure 2). Also QUICKI was impaired in the PE group ( $P$ time $=0.051, P$ group $=0.023$, and $P$ time $\times$ group $=0.420)$. Similar significant results for ICAM, VCAM, FMD, glucose tolerance (HOMA and QUICKI) and systolic blood pressure during the 11 years of follow-up were obtained when the potentially confounding effects of BMI was taken into account (data not shown).

\section{DISCUSSION}

Few studies in women with a pregnancy complicated by PE have repeated assessments of vascular function during a long follow-up. Participants in the current study were examined at 1 and 11 years following the index pregnancy. We show a sustained elevated blood pressure and unfavorable cardiovascular risk factor profile but improvement of the initially impaired endothelial function in women with a previous $\mathrm{PE}$, as compared with subjects with a normal pregnancy. This may have important implications for cardiovascular prevention.

Previous studies show that patients with a history of PE have an elevated blood pressure later in life. However, few studies have reported blood pressure values during pregnancy and also performed repeat blood pressure measurements during long-term follow-up. ${ }^{13}$ We report a trend for elevated casual blood pressure levels in the PE group at both 1 and 11 years after the index pregnancy. In support of these results, we found higher $24 \mathrm{~h}$ ambulatory blood pressure values at night and an impaired night/day ratio in the PE group. This is in agreement with findings 2 to 12 years following PE. ${ }^{14}$ This is an important finding as ambulatory blood pressure recordings predict future cardiovascular events better than casual blood pressure values. Nighttime values seem to provide the strongest prognostic information, and the night/day ratio adds independent prognostic information. ${ }^{15}$ Of note, the differences in blood pressure between the two study groups were small and the study groups are small. However, as there is a strong blood pressure tracking from young age to adulthood, and blood pressure levels at young age predict future hypertension, cardiovascular morbidity and mortality, ${ }^{16-18}$ this may contribute to the future cardiovascular risk observed in subjects with a previous PE. ${ }^{1}$

Indices of arterial stiffness (that is, pulse wave velocity and augmentation index) were similar in the two study groups 11 years after the index pregnancy. An increased arterial stiffness in pregnant women has been associated with the development of PE. ${ }^{19}$ However, only few small studies have examined arterial stiffness in women following PE. Evans et al. ${ }^{20}$ examined women with PE and showed a normal pulse wave velocity after 16 months of follow-up. Rönnbäck et al. $^{21}$ found no increased augmentation index in a cross sectional study of non-pregnant women $\sim 5$ years after a history of PE, whereas
Lampinen et l. $^{22}$ in another cross sectional study reported same augmentation index values in women with a history of PE and those with a normal pregnancy 5 to 6 years post partum. ${ }^{22}$ Compared with women with a previous normal pregnancy, Pàez et al. ${ }^{23}$ reported that subjects with history of PE examined 2 to 3 years post partum had normal pulse wave velocity but an increased augmentation index. Also, an increased augmentation index in women with a history of early-onset PE or intrauterine growth retardation (but not in lateonset PE) investigated 6 to 24 months after their delivery, as compared with women with a prior normal pregnancy has been reported. ${ }^{24}$ Taken together, our results extend previous findings and suggest that arterial stiffness is normal in subjects also 11 years after a pregnancy complicated with PE.

In agreement with others, ${ }^{25,26}$ we have reported that patients with a history of PE have impaired endothelial function, assessed by FMD 1 year following delivery. ${ }^{4}$ The novelty of our current study is the demonstration of temporal changes, and the long follow-up. A major finding when examined again 11 years following the index pregnancy is that endothelial function by FMD was normalized in the PE group, whereas values remained unchanged in the control group. The FMD technique reflects conduit artery endothelial function, while pulse wave analysis with terbutaline provocation provides information on resistance artery endothelial function. ${ }^{10}$ Thus, our findings of similar reflectance index values provide further support of a normalized endothelial function in the PE group after 11 years. However, more detailed information of the time course for the changes in endothelial function cannot be provided by the current results.

Our results should be interpreted with caution as the small number of subjects may have affected the ability to detect small differences in endothelial function between the two study groups. Also, increases in hyperemic blood flow that represent endothelial stimulation was greater in the control group, which may be taken to suggest FMD to be greater in the control group. However, this seems less likely because the ratios of post ischemic hyperemia-/glyceryl trinitrate-induced response were similar in the two study groups. Thus, our results are in agreement with results of similar microvascular hyperemic response in women with a history of $\mathrm{PE}$ and subjects with an uneventful pregnancy 23 years after their delivery. ${ }^{27}$ Furthermore, other cross sectional studies with forearm venous occlusion plethysmography and intra-arterial infusions of acetylcholine and sodium nitroprusside showed a similar endothelial function index in women 5 to 6 years after a history of PE and in those with a normal pregnancy, ${ }^{22}$ and peripheral arterial tonometry combined with reactive hyperemia demonstrated similar endothelial function in women with PE and in normal pregnancies 5 to 8 years post partum. ${ }^{27}$ That study, however, provided evidence of endothelial dysfunction in women and children of PE when combined with a small for gestational age infant pregnancy.

Forearm hyperemic blood flow velocity is related to major cardiovascular risk factors. This has been suggested to be due to the effects of risk factors on the vasodilatation in the resistance arteries determining hyperemic blood flow. ${ }^{29}$ Systolic blood flow velocity in conduit arteries is affected by arterial stiffness, and blood flow during systole is related to coronary artery disease risk and carotid atherosclerosis. ${ }^{30,31}$ Accordingly, we observed higher forearm systolic blood flow velocities in the PE groups than in the control group, consistent with more cardiovascular risk factors in subjects with a history of PE. This supports the findings of decreased small and large artery elasticity, and higher body mass index, blood pressure, hs-CRP and triglyceride values in women with a history of early-onset PE, after 4 years of follow-up. ${ }^{32}$ Although we observed similar values for 
endothelial function by FMD and by pulse wave analysis with terbutaline provocation in both study groups, our findings of higher forearm systolic blood flow velocities in the PE group may suggest that subjects with a history of PE can have subtle abnormalities in arterial structure and endothelial function due to shared pre-existing risk factors.

Markers of inflammation (that is, hs-CRP) and endothelial activation (that is, ICAM, VCAM) were reduced from 1 to 11 years of follow-up. However, ICAM remained higher in the PE group at 11 years, as compared with the control group. This confirms previous observations made 15-25 years after an index pregnancy with PE. ${ }^{33}$ We have previously shown other markers of endothelial dysfunction (sFlit-1, PlGF) to be elevated during PE. ${ }^{4}$ However, in the present investigation after 11 years sFlit-1 and PlGF were similar in both study groups. This is in agreement with observations up to 9 years following early and severe $\mathrm{PE},{ }^{24,34}$ but contrasts findings by others with a shorter follow-up. ${ }^{27}$ Furthermore, TNF receptor 1 was elevated in the PE group. TNF receptor 1 has been suggested to be cardioprotective and is upregulated by $\mathrm{TNF} \alpha$ activation, which is likely to promote the inflammatory cascade within the arterial wall during the development of atherosclerosis. ${ }^{35}$ However, another study investigating inflammatory markers 20 years post partum failed to demonstrate increased levels of $\mathrm{TNF} \alpha$, in contrast to findings 12-14 weeks post partum. ${ }^{36,37}$ Thus, our and other findings suggest that $\mathrm{PE}$ is associated with inflammatory and endothelial activation, which may not be fully normalized within 11 years. ${ }^{14,28}$ This could be of clinical importance as biomarkers for inflammation and endothelial activation have been associated with an increased risk of future cardiovascular disease. ${ }^{38,39}$

We found an impaired glucose tolerance during the 11 years of follow-up in subjects with a history of PE, and glucose intolerance was related to body mass index. This is in agreement with other observations. $^{3}$ Thus, women with a history of PE show light but sustained alterations at both 1 and 11 years after the index pregnancy concerning body size, glucose control, inflammation and blood pressure, with similarities to the metabolic syndrome, a condition associated to future cardiovascular complications.

In conclusion, our results of higher blood pressures and impaired glucose tolerance 11 years after a pregnancy complicated by PE suggest that pre-existing risk factors may be more important than a permanent damage of the endothelium for future cardiovascular complications in women with a history of PE. This may suggest that these risk factors are present already before the pregnancy. ${ }^{5}$ Thus, one may consider all women with prior PE to carry a risk for future cardiovascular disease. This highlights the importance of obtaining a detailed pregnancy history in everyday clinical practice as a simple measure to improve cardiovascular risk assessment and allow for early institution of early risk preventive measures. Early treatment of risk factors is likely to be of benefit in order to prevent cardiovascular disease. Whether earlier and more aggressive therapeutic interventions will reduce risk in a cost-effective manner, however, remains to be studied. ${ }^{40}$

\section{CONFLICT OF INTEREST}

The authors declare no conflict of interest.

\section{ACKNOWLEDGEMENTS}

The expert technical assistance by Ms Jenny Rasck and Eva Wallén is greatly acknowledged. Supported by Karolinska Institutet, Stockholm, Sweden.
1 Bellamy L, Casas JP, Hingorani AD, Williams DJ. Pre-eclampsia and risk of cardiovascular disease and cancer in later life: systematic review and meta-analysis. BMJ 2007; 335: 974

2 McDonald SD, Malinowski A, Zhou Q, Devereaux PJ. Cardiovascular sequelae of preeclampsia/eclampsia: a systematic review and meta-analyses. Am Heart J 2008; 156: 918-930

3 Lykke JA, Langhoff-Roos J, Sibai BM, Funai EF, Triche EW, Paidas MJ. Hypertensive pregnancy disorders and subsequent cardiovascular morbidity and type 2 diabetes in the mother. Hypertension 2009; 53: 944-951.

4 Hamad RR, Eriksson MJ, Silveira A, Hamsten A, Bremme K. Decreased flow-mediated dilation is present 1 year after a pre-eclamptic pregnancy. J Hypertens 2007; 25: 2301-2307.

5 Romundstad PR, Magnussen EB, Smith GD, Vatten LJ. Hypertension in pregnancy and later cardiovascular risk: common antecedents? Circulation 2010; 122: 579-584.

6 Davey DA, MacGillivray I. The classification and definition of the hypertensive disorders of pregnancy. Am J Obstetr Gynecol 1988; 158: 892-898.

7 Laurent S, Cockcroft J, Van Bortel L, Boutouyrie P, Giannattasio C, Hayoz D, Pannier B, Vlachopoulos C, Wilkinson I, Struijker-Boudier H, European Network for Non-invasive Investigation of Large Arteries. Expert consensus document on arterial stiffness: methodological issues and clinical applications. Eur Heart J 2006; 21: 2588-2605.

8 Corretti MC, Anderson TJ, Benjamin EJ, Celermajer D, Charbonneau F, Creager MA Deanfield J, Drexler H, Gerhard-Herman M, Herrington D, Vallance P, Vita J, Vogel R, International Brachial Artery Reactivity Task Force. Guidelines for the ultrasound assessment of endothelial-dependent flow-mediated vasodilation of the brachial artery: a report of the International Brachial Artery Reactivity Task Force. J Am Coll Cardiol 2002; 39: 257-265.

9 Wilkinson IB, Hall IR, MacCallum H, Mackenzie IS, McEniery CM, van derArend BJ, Shu YE, MacKay LS, Webb DJ, Cockcroft JR. Pulse-waveanalysis: clinical evaluation of a noninvasive, widely applicable method for assessing endothelial function. Arterioscler Thromb Vasc Biol 2002; 22: 147-152.

10 Lind L, Fors N, Hall J, Marttala K, Stenborg A. A comparison of three different methods to evaluate endothelium-dependent vasodilation in the elderly: the Prospective Investigation of the Vasculature in Uppsala Seniors (PIVUS) study. Arterioscler Thromb Vasc Biol 2005; 25: 2368-2375.

11 Matthews DR, Hosker JP, Rudenski AS, Naylor BA, Treacher DF, Turner RC Homeostasis model assessment: insulin resistance and beta-cell function from fasting plasma glucose and insulin concentrations in man. Diabetologia 1985; 28 412-419.

12 Katz A, Nambi SS, Mather K, Baron AD, Follmann DA, Sullivan G, Quon MJ. Quantitative insulin sensitivity check index: a simple, accurate method for assessing insulin sensitivity in humans. J Clin Endocrinol Metab 2000; 85: 2402-2410.

13 Nordén Lindeberg S, Hanson U. Hypertension and factors associated with metabolic syndrome at follow-up at 15 years in women with hypertensive disease during first pregnancy. Hypertens Pregnancy 2000; 19: 191-198.

14 Mangos GJ, Spaan JJ, Pirabhahar S, Brown MA. Markers of cardiovascular disease risk after hypertension in pregnancy. J Hypertens 2012; 30: 351-358.

15 Hansen TW, Li Y, Boggia J, Thijs L, Richart T, Staessen J. Predictive role of the nighttime blood pressure. Hypertension 2011; 57: 3-10.

16 Chen X. Wang Y. Tracking of blood pressure from childhood to adulthood: a systematic review and meta-regression analysis. Circulation 2008; 117: 3171-3180.

17 Conen D, Tedrow UB, Koplan BA, Glynn RJ, Buring JE, Albert CM. Influence of systolic and diastolic blood pressure on the risk of incident atrial fibrillation in women. Circulation 2009; 119: 2146-2152.

18 Sundström J, Neovius M, Tynelius P, Rasmussen F. Association of blood pressure in late adolescence with subsequent mortality: cohort study of Swedish male conscripts. BMJ 2011; 22: d643.

19 Hausvater A, Giannone T, Sandoval YH, Doonan RJ, Antonopoulos CN, Matsoukis IL, Petridou ET, Daskalopoulou SS. The association between preeclampsia and arteria stiffness. J Hypertens 2012; 30: 17-33.

20 Evans CS, Gooch L, Flotta D, Lykins D, Powers RW, Landsittel D, Roberts JM, Shroff SG. Cardiovascular system during the postpartum state in women with a history of preeclampsia. Hypertension 2011; 58: 57-62.

21 Rönnbäck M, Lampinen K, Groop PH, Kaaja R. Pulse wave reflection in currently and previously preeclamptic women. Hypertens Pregnancy 2005; 24: 171-180.

22 Lampinen KH, Rönnbäck M, Kaaja RJ, Groop PH. Impaired vascular dilatation in women with a history of pre-eclampsia. J Hypertens 2006; 4: 751-756.

23 Pàez O, Alfie J, Gorosito M, Puleio P, de Maria M, Prieto N, Majul C. Parallel decrease in arterial distensibility and endothelium-dependant dilatation in young women with a history if pre-eclampsia. Clin Exp Hypertens 2009; 31: 544-552.

24 Yinon Y, Kingdom JCP, Odutayo A, Moineddin R, Drewlo S, Lai V, Cherney DZI, Hlasunewich MA. Vascular dysfunction in women with a history of preeclampsia and intrauterine growth restriction. Circulation 2010; 122: 1846-1853.

25 Spaan J, Houben A, Musella A, Ekhart T, Spanderman M, Peeters L. Insulin resistance relates to microvascular reactivity 23 years after preeclampsia. Microvasc Res 2010; 80: $417-421$.

26 Chambers JC, Fusi L, Malik IS, Haskard DO, De Swiet M, Kooner JS. Association of maternal endothelial dysfunction with preeclampsia. JAMA 2001; 285: 1607-1612.

27 Germain AM, Romanik MC, Guerra I, Solari S, Reyes MS, Johnson RJ, Price K, Karumanchi SA, Valdés G, Mitchell GF. Endothelial dysfunction: a link among preeclampsia, recurrent pregnancy loss, and future cardiovascular events? Hypertension 2007; 49: 90-95. 
28 Kvehaugen AS, Dechend R, Ramstad HB, Troisi R, Fugelseth D, Staff AC. Endothelial function and circulating biomarkers are disturbed in women and children after preeclampsia. Hypertension 2011; 58: 63-69.

29 Mitchell GF, Parise H, Vita JA, Larson MG, Warner E, Keaney JF Jr, Keyes MJ, Levy D, Vasan RS, Benjamin EJ. Local shear stress and brachial artery flow-mediated dilation: the Framingham Heart Study. Hypertension 2004; 44: 134-139.

30 Järhult SJ, Hall J, Lind L. Hyperaemic blood-flow velocities in systole and diastole relate to coronary risk in divergent ways. Clin Physiol Funct Imaging 2008; 28: 189-195.

31 Järhult SJ, Sundström J, Lind L. Brachial artery hyperemic blood flow velocities are related to carotid atherosclerosis. Clin Physiol Funct Imaging 2009; 29: 360-365.

32 Souwer ET, Blaauw J, Coffeng SM, Smit AJ, Van Doormaal JJ, Faas MM, Van Pampus MG. Decreased arterial elasticity in formerly early-onset preeclamptic women. Acta Obstet Gynecol Scand 2011; 90: 797-801.

33 Sattar N, Ramsay J, Crawford L, Cheyne H, Greer IA. Classic and novel risk factor parameters in women with a history of preeclampsia. Hypertension 2003; 42 : 39-42.

34 Gaugler-Senden IP, Tamsma JT, van der Bent C, Kusters R, Steegers EA, de Groot CJ. Angiogenic factors in women ten years after severe very early-onset preeclampsia. PLoS One 2012; 7: e43637.
35 Pai JK, Pischon T, Ma J, Manson JE, Hankinson SE, Joshipura K, Curhan GC, Rifai N, Cannuscio CC, Stampfer MJ, Rimm EB. Inflammatory markers and the risk of coronary heart disease in men and women. N Engl J Med 2004; 351: 2599-2610.

36 Vitoratos N, Economou E, lavazzo C, Panoulis K, Creatsas G. Maternal serum levels of TNF-alpha and IL-6 long after delivery in preeclamptic and normotensive pregnant women. Mediator Inflamm 2010; 2010: 908649.

37 Freeman DJ, McManus F, Brown EA, Cherry L, Norrie J, Ramsay JE, Clark P, Walker ID, Sattar N, Greer IA. Short- and long-term changes in plasma inflammatory markers associated with preeclampsia. Hypertension 2004; 44: 708-714.

38 Tzoulaki I, Murray GD, Lee AJ, Rumley A, Lowe GD, Fowkes FG. C-reactive protein, interleukin-6, and soluble adhesion molecules as predictors of progressive peripheral atherosclerosis in the general population: Edinburgh Artery Study. Circulation 2005; 112: 976-983.

39 van der Meer IM, de Maat MP, Bots ML, Breteler MM, Meijer J, Kiliaan AJ, Hofman A, Witteman JC. Inflammatory mediators and cell adhesion molecules as indicators of severity of atherosclerosis: the Rotterdam Study. Artherioscler Thromb Vasc Biol 2002; 22: 838-842.

40 Spaan J, Peeters L, Spaanderman M, Brown M. Cardiovascular risk management after a hypertensive disorder of pregnancy. Hypertension 2012; 60: 1368-1373. 